\title{
SOME PROBLEMS IN NOMENCLATURE.*
}

By E. P. Felt.

Stability of nomenclature is greatly to be desired. It is, in our estimation, more important than that an investigator should have every particle of credit for discovering or recording the presence of a species, though the latter should not be ignored by any means. Certain peculiar questions in nomenclature exist in the Cecidomyiidae, a group in which we are much interested. It is hoped that this paper will provoke discussion and result in an agreement which will go far towards solving some vexatious questions. We desire at the outset to make this discussion absolutely impersonal, and for that reason the writer has taken the legal impersonal John Doe and some of his cousins to exemplify actual conditions or to illustrate situations which might arise. No significance should be attached to the dates employed, since they have no reference to real cases. Furthermore the names employed are nomina nuda and have no standing in nomenclature.

\section{CASE I.}

1475. Cecidomyia floricola-Given by John Doe to yellowish Cecidomyiid larvae in unopened spiraea blossoms.

1478. Cecidomyia floricola, C. flavescens and Dasyneura abdominalis-All reared from the same blossoms by Edward Doe.

To what species did the larva observed by John Doe in $\mathbf{I} 475$ belong? Can he, by any possibility, claim authorship to a species?

CASE 2.

I 492. Cecidomyia gallicola-Described from the gall only, by John Doe.

I 499. Cecidomyià gallicola-Adult reared and described by John Doe.

Does the species date back to $149^{2}$ and that name carry? We will suppose, for the sake of argument, that it does. Fortunately or unfortunately Richard Doe in 1575 discovered that Cecidomyia gallicola (John Doe I499) is not the maker of the gall but an inquiline. He describes the maker of the gall as Lasioptera gallicola (John Doe I492) and proposes for Cecidomyia gallicola (John Doe. r 499) Cecidomyia alboscuta. Furthermore,

* Read at the Chicago meeting. 
Edward Doe in 1575 , though a few months later, reared still another species from this same gall. He likewise concludes that he has the true gall maker and describes it as Dasyneura gallicola (John Doe 1492). It happens that both the Lasioptera and the Dasyneura may produce this gall. Again we must ask the question: Can the gall carry the name? It is evident in this case that the systematic name, the one appearing in a catalogue listing the species of this family, is based and must of necessity be based on the characters presented by the $\varepsilon$ dult. There are cases where two species belonging to the same genus may be bred from the same gall. Is there a Solomon present who can inform us which species shall bear the name earlier bestowed upon the gall? The situation is further complicated by the fact that it is very easy to rear Cecidomyiidae from some portion of a plant supposedly uninfested, as for example, apparently normal flowers, leaves or even stems.

\section{CAsE 3.}

I496. Cecidomyia abstrusa-Gall described and the larva characterized by John Doe, so that it can possibly be referred to a genus.

1497. Lasioptera cincta-Collected at large and described by William Doe.

r 499. Lasioptera abstrusa and L. splendens-Bred and described by Edward Doe.

Subsequent studies proved that both species may occur in about equal numbers in the gall. There are no characters given in the first description that can be relied upon to separate the larvae of the two forms. Was the species described in 1496 , if so, what species? Furthermore, the adult described by Edward Doe as Lasioptera abstrusa in 1499 , proves to be the same as the one William Doe collected and described in 1497.

There is little question as to what disposition should be made of case I. A close examination of case 2 shows that ultimately the name must be carried by the adult. Would it not be in the interest of stability of nomenclature to accept the bestowal of the earlier names upon galls only in the spirit in which they were conferred; namely, as tentative pending the discovery and characterization of the imago? It is only a very little step farther to put in the same category, galls accompanied by a very brief description of the larva as illustrated in Case 3. We fully agree with the 
suggestion that wherever possible the name bestowed upon the gall, should be given to the adult when reared therefrom. Unfortunately this is not always possible, since no one would for a moment allow that it was necessary to rear from a gall before describing the adult. It would be impossible and entircly impractical to attempt to enforce any such limitation, consequently sooner or later some decision must be made as to what constitutes a valid description in this group, as there are cases where species have been based on characters presented by the galls and subsequently the adults described. Despite the fact that we desire to be courteous to earlier workers and credit them with all due honor, nevertheless we must establish some standard in order to obtain a satisfactory working basis. The insistence that the true maker of the gall bear the same specific name as was originally bestowed upon the vegetable deformity it inhabits, will surely result in an almost unending series of unrivaled synonymical gymnastics, amusing though hardly edifying. 